\title{
Notas micológicas XI:Tritirachium oryzae, Paecilomyces formosus y alcances en la Sección Fumigati de Aspergillus con énfasis en el complejo Aspergillus viridinutans
}

\author{
(Micological notes XI: Tritirachium oryzae, Paecilomyces formosus, and extent \\ in the Section Fumigati with enfasis in the Aspergillus viridinutans complex)
}

\author{
Eduardo Piontelli,L, ${ }^{1 *}$ Rodrigo Cruz, $C^{2}$ \& JoséAmaro, $S^{3}$ \\ 1,2Universidad de Valparaíso, Escuela de Medicina, \\ ${ }^{3}$ Cátedra de Micología. Casilla 92V. Valparaíso \\ Universidad de Chile, Facultad de Medicina. \\ Laboratorio de Micología. \\ *Autor para correspondencia: eduardopiontelli@ hotmail.com
}

\section{RESUMEN}

En estas notas micológicas, se comentan los aspectos taxonómicos, ecológicos fisiológicos y moleculares de 2 especies fúngicas filamentosas oportunistas en humanos tales como: Tritirachium oryzae y Paecilomyces formosus, poco conocidas en su distribución en Chile. Al mismo tiempo se aportan datos recientes de la literatura referentes a la distribución y patología de los nuevos integrantes de de la sección Fumigati de Aspergillus, con énfasis en el complejo A. viridinutans, un grupo de especie morfológicamente similares y generalmente oportunista en humanos y animales, las cuales no han sido bien definidas en la últimas décadas.

Tritrachium oryzae (Vincent)de Hoog. Studies in Mycology 1:12(1972)

=Beauveria oryzae Vincens: 122 (1910)

=Beauveria brumptii Langeron \& Lichaa: 133 (1934)

=Spirotrichum purpureum Saito: 1 (1939)

=Spirotrichum musae J.F.H. Beyma, Antonie van

Leeuwenhoek 6: 288 (1940)

=Tritirachium purpureum Saito ex J.F.H. Beyma, Antonie van Leeuwenhoek 8: 118 (1942)

=Tritirachium roseum J.F.H. Beyma, Antonie van

Leeuwenhoek 8: 119 (1942)

=Tritirachium violaceum Tatarenko: 90 (1952)

El géneroTritirachium Limber (sp.tipo T. dependens Limber), contiene principalmente especies anamórficas clasificadas históricamente en la absoleta clase hyphomycetes, posteriormente ubicadas en incertae sedis dentro de los Pezizomycotina (Ascomycota), con 3 especies comúnmente aceptadas (van Beyma 1942; de

\begin{abstract}
In these notes, taxonomic, ecological, physiological and molecular aspects are discussed of two opportunistic filamentous fungal species in humans, such as Tritirachium oryzae and Paecilomyces formosus, little known in its distribution in Chile. While recent literature data concerning the distribution and pathology of the new members of the Aspergillus section Fumigati contribute, emphasizing the complex A. viridinutans, a group of morphologically similar species and generally opportunistic in humans and animals did, which have not been well defined in recent decades.
\end{abstract}

Hoog 1972; Kirk et al. 2008). La especie tipo, obtenida desde raíces muertas deYucca treculeana Carrière, desde Cuba, fue separada de Verticillium por Limber (1940), y su nueva nominación genérica se basó en la similitud de su conidióforo geniculado al raquis del trigo (Triticum). El género estuvo integrado por otras especies, muchas de ellas actualmente en sinonimía o incluidas en los Clavicipitaceae (MacLeod 1954; de Hoog 1972; Kirk et al. 2008) y aparentemente, solo se reconocen en la actualidad 6, dos de ellas aún no determinadas ( Schell et al., 2011). Estos últimos autores mediante biología molecular con multigenes y 14 aislados, confirmaron que sus linajes no tenían relación con las Clavicipitaceae u otros Ascomycota, sino con los Pucciniomycotina en Basidiomycota (en los nuevos taxas: Tritirachiomycetes, Tritirachiales Tritirachiaceae), los cuales presentan hifas multinucleadas, poro septal simple, conidióforos subhialinos a dematiaceos, con células conidiógenas simpodiales subhialinas a dematiaceas que se presentan en racimos o desordenadas, con conidios sobre un elongado raquis. 


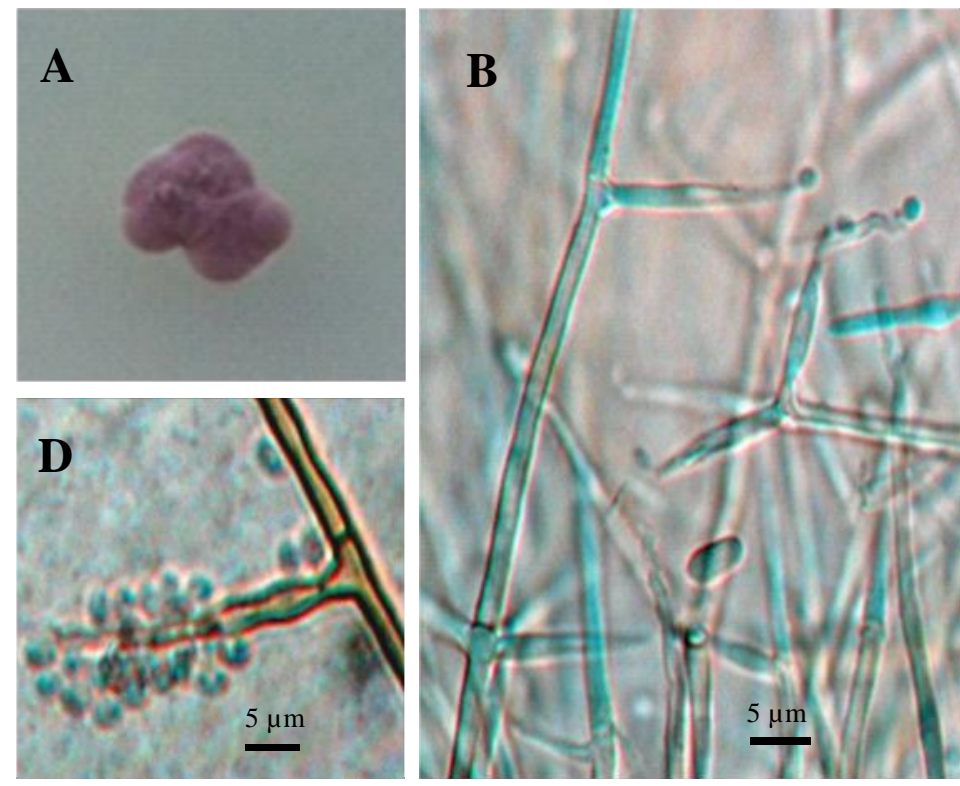

Figura1. A-B-C-D. Tritirachium oryzae. A. colonia en PDA, B. Conidióforos con ramificación en cultivos jóvenes, $\mathrm{C}$. Conidióforos ramificados y células conidiales elongadas formando un raquis, $D$. Célula conidiógena y conidios.

Teleomorfo desconocido y no descrito en ninguna especie. Shell et al.(2011), comentan que la sola identificación con criterios morfológicos es problemática en el taxon y que sus análisis filogenéticos no soportan la circunscripción existente de algunas especies. Reintroducen T.roseum por ser su extipo claramente diferente de los aislados de $T$. oryzae. Concluyen además que la cepa, NRRL 2312, T.album Limber (=Engyodontium álbum (Limber) de Hoog), muestra por las secuencias de ITS que es un miembro de las Clavicipitaceae en congruencia con su clasificación (de Hoog 1972), mientras las secuencias del extipo def Tritirachium cinnamomeum, considerado un miembro de Nodulisporium (Xylariales, Asocomycota), indican que pertenece al género Tritirachium (de Hoog 1972), Hugues et al. (2012), al estudiar molecularmente una especie morfológicamente similar a Nodulisporium (N.cylindroconium), previamente descrita como 'Tritirachium sp.', observaron que se agrupaba cerca de Tritirachium en los Pucciniomycotina, sin embargo, debido a su diferente conidiogénesis, propusieron, el nuevo género Paratritirachium.

Basándose en caracteríatricas macro y microscópicas, las especies más comunes como, T. dependens y T. oryzae, pueden separarse rápidamente debido a que el primero presenta tonos cafesosos y conidióforos frecuentemente ramificados; cada rama termina en un racimo de células conidiógenas simpodiales. Mientras $\boldsymbol{T}$. oryzae tiene colonias generalmente en tonos vináceospúrpura y conidioforos que se ramifican raramente (van Beyma,1942, de Hoog 1972, Limber 1940, Mehrotra and Basu 1967). Sin embargo, puede encontrarse una sobreposición de algunas características morfológicas entre T.dependens y $T$. cinnamomeumm o entre T.oryzae / T. roseum, y los conidios de algunas de estas 4 cepas, son bastante similares en tamaño ( Schell et al. 2011), lo que puede erróneamente colocar el aislado en cualquiera de los 2 grupos.

Las especies deTritirachium no son muy comunes e integran una pequeña parte de la biota fúngica. Es un género relacionado con Beauveria, Engyodontium y Aphanocladium (De Hoog 1972-1973; Gams et al, 1984). Sus especies parecen ser saprotrofas, en ambientes diversos así como patógenas de insectos (Pakshir, et al., 2013). Incluso se ha detectado una especie en ambientes marinos (T.album)( Wiese et al.2011), mientras T.oryzae, se presenta en suelo, aire, vegetación y ambientes internos (Samson 2009), no existe información relacionada a la inhalación de sus conidios y los posibles efectos tóxicos o alergénicos. Se ha detectado en superficies mediante métodos de impresión y muestras de aire cultivables (aparato de Anderson u otros por impacto), sin embargo, como sus esporas no tienen una distintiva morfología en las muestras obtenidas por impacto, se caracterizan como «otros conidios sin color». Se aísla con cierta frecuencia desde papel, yute, textiles, adhesivos, y papeles murales. Su habitat natural es el suelo y material vegetal en descomposición, sin embargo, debido a su capacidad de crecer lentamente a $37^{\circ} \mathrm{C},($ Fig. $1 \mathrm{~A})$, raramente se ha reportado en infecciones oportunistas de la cornea (Rodrigues \& Laibson 1975), dermatomicosis del cuero cabelludo (Moraes et al. 2010), así como en onicomicosis Naseri, et al., 2013). No hay mucha información sobre la 
capacidad patogénica de los miembros de esta nueva familia Tritiraciaceae, salvo la capacidad de T. álbum de producir una serina proteasa. En general las proteasas ejecutan una larga variedad de funciones ya sea a nivel celular como a nivel de órganos, para producir un sistema de cascada, como hemostasis e inflamación y ser responsables de procesos complejos en la fisiología de la célula como también en producir anormales condiciones patofisiológicas (Rao et al. 1998).

Nuestro aislado proviene de una muestra de expectoración de una mujer de 48 años, con antecedentes de EPOC y descompensaciones frecuentes durante el último año. Por presentar imagenes radiológicas de probable sobreinfección atipica, se solicitó cultivo de expectroración (positivo) y luego lavado broncoalveolar (en este ultimo no hubo desrarrollo del hongo), por lo que se interpretó como una contaminación ambiental.

T. oryzae (T. roseum es muy semejante), tiene colonias de colores vináceos-lila pálido (Fig. 1A).El reverso tiene una coloración que varía del rojo café pálido a café rojizo oscuro; olor ausente. El micelio produce conidióforos que tienen ramas laterales con puntas que terminan en zig zag, característicos en el género. Conidioforos y células conidiógenas dematiáceas para todos los aislados, caracterizadas por un fértil y elongado raquis; conidios hialinos (ocasionalmente subhialinos), unicelulares, esféricos a elipsoidales, $2.1-3.3 \times 1.6-2.6 \mu \mathrm{m}$ (media $2.5 \mathrm{x}$ 2.1 $\mu \mathrm{m})$.

Los conidios de las diferentes especies son también hialinos (occasionalmente subhialinos), unicelulares y sus medidas son las siguientes: T. dependens (holotipo) 2.7$4.0 \times 2.2-3.3 \mu \mathrm{m}$ (media $3.2 \times 2.5) ;$ T. dependens (cultivo) 2.9-4.1 x 1.8-3.2 $\mu \mathrm{m}$ (media 3.3 x 3 2.7); T.cinnamomeum 3,6 -5,4 x 2.4-3.4 $\mu$ m (media $4.2 \times 2.9) ; \boldsymbol{T}$. sp. (CBS 265.96) 2.4-4.2 x 1.9-3.3 $\mu \mathrm{m}$ (media 3,6 x 2,8); T. oryzae 2.1-3.3 x 1.6$2.6 \mu \mathrm{m}$ (media $2,5 \times 2,1$ ). Las dificultades en identificar los aislados basándonos solo en la morfología, se complican por la falta de aislados de las varias especies, mientras $\boldsymbol{T}$. oryzae es la única especie bien representada en las colecciones de cultivos.

Nuestro aislado no difiere mayormente de la descripción de de Hoog (1972), sin embargo, nos interesó su crecimiento lento a $37^{\circ} \mathrm{C}(6-7 \mathrm{~mm}$ en 10 días en MEA), colonias de un color violeta pálido (Fig.1 A) y un reverso café vináceo, micelio hialino a cafesoso en el tiempo,con conidióforos angostos de color café, lisos (2-3 $\mu \mathrm{m})$, con células conidiógenas que se presentan en la parte más apical, dispuestas solitarias a ambos lados y a veces en pequeños racimos de 2-3, en forma verticilada, dilatadas en su base y adelgazándose hacia el ápice formando un raquis geniculado de $25-30 \times 1 \mu \mathrm{m}$, (Fig.1D), pero algunos bastante más largos y que presentan en ambos lados conidios hialinos, lisos, de paredes delgadas, subglobosos a elipsoidales, 2-3 (-3,3) x 1,5- $3 \mu \mathrm{m}$ (Fig.1C). Clamidosporas ausentes. Teleomorfo ausente después de 30 días.
Schell et al. (2011), en sus observaciones con el microscopio electrónico de transmisión revelaron la presencia de un poro simple, uniperforado, con ausencia de doliporos y cuerpos Woronin en las hifas de T. euginum (una característica de los Basidiomycetes en la subdivisión Pucciniomycotina.

El diagnostico molecular de $T$. oryzae puede confirmarse por secuencias de PCR de los espacios de transcripción interna de los genes de DNAr. In vitro los test de susceptibilidad han demonstrado su sensibilidad al itraconazol y posaconazol ( Naseri et al2013). Shell et al.(2011), en la descripción de los integrantes de la nueva clase Tritirachiomycetes, analizaron las regiones de 4 genes (las largas subunidades nucleares, las pequñas subunidades nucleares, DNA, espacios de regiones de transcripción interna, incluyendo las subunidades $5.8 \mathrm{~S}$ del DNAr, las subunidades de DNAr y el factor de translación de elongación $1 \alpha$. Además de datos de secuencias adicionales de DNA-directo, RNA polimerasa subunidad II para algunas especies.

Wyk et al. (2000), comentan que uno de los métodos fáciles de reconocer, la conidiogénesis simpodial, es siguiendo el brote hacia afuera de un primer conidio apical, donde la célula conidiógena rápidamente se extiende hacia un nuevo punto de crecimiento justo atrás y a un lado del primer conidio, formando un nuevo ápex, el cual se convierte en un nuevo conidio y así sucesivamente hasta repetirse muchas veces en algunos taxas, quedando los conidios adheridos sin ser desplazados por el renovado crecimiento del conidióforo. En estos taxas después de una conidiogénesis repetida, la célula se alarga y presenta una larga cadena de conidios a su alrededor.Cuando los conidios se han desprendido se aprecia la apariencia de un raquis como en Tritirachium y Acrodontium (Hughes, 1953; de Hoog, 1972; Carmichael et al, 1980; van Wyk et al, 2000)

La nueva especie Tritirachium egenum otro biotrófico micosimbionte, fue encontrado creciendo en asociación con Penicillium rugulosum (Beguin, 2010), destacándose que entre los hongos micosimbiontes la estrategia nutricional que presenta $T$. egenum es nueva, debido a que no vive en estrecha asociación con el citoplasma de su hospedador. A pesar de no ser un micosimbionte haustorial ni de contacto (los 2 grupos en que se clasifican los endosimbiontes), su estrecha asociación se basa en la utilización de sideróforos, una asociación interfúngica que no ha sido reportada.

Toome \& Aime(2011), mencionan que las 6 especies de Tritirachium conocidas, son todas anamórficas y se desconoce su estado sexual. La especie tipo T.dependens Limber, fue descrita desde raices muertas de Yucca treculeana en Cuba (Limber 1940); la misma especie, fue encontrada subsecuentemente en la pared de un sótano en Belgica (Beguin 2010; Schell et al. 2011). Mientras el rol específico de las species de Tritirachium en el ambiente no se conocen, hay evidencias que $\boldsymbol{T}$. dependens es una 
especie potencialmente asociada a las especies de Penicillium por la dependencia de ciertos micronutrientes. Dos especies; T. oryzae (Vincens) de Hoog yT. roseum J.F.H. Beyma, se han aislado como saprotrofos (decomponedores), desde varios ambientes internos, pero también de alguna infecciones superficiales en humanos (Moraes et al. 2010; Rodrigues \& Laibson, 1975). Tritirachium cinnamomeum J.F.H. Beyma, es representado solo por un especimen, aislado de una mosca en Holanda. Las 2 especies remanentes recientemente identificadas necesitan futuros estudios (Schell et al. 2011). La biología de los miembros de este grupo fúngico es aún poco conocida $\mathrm{y}$ la importancia sobre su potencial médico se ha estudiado con ciertos detalles.

Según Shell et al. (2011), la descripción de T.eugenum no parece ser diferente de la descripción de $\boldsymbol{T}$. dependens. Sus análisis de las regiones ITS, muestran que es idéntico a las secuencias de ITS del holotipo, y concluyen que la especie es un sinónimo obligado de $\boldsymbol{T}$. dependens. Historicamente, T. dependens y T. oryzae, se pueden separar rápidamente mediante caracteres macromicroscópicos.

T. dependens tiene colonias de color en tonos de bronceados y sus conidióforos se ramifican frecuentemente y cada rama termina en un racimo verticilado de células conidiógenas simpodiales, mientras la colonia de T. oryzae tiene colores en tonos vináceos -púrpura y los conidióforos se ramifican solo raramente (van Beyma,1942; de Hoog 1972; Limber 1940; Mehrotra \& Basu 1967). Además los conidios de T. dependens (IHEM 3497), $\boldsymbol{T}$. cinnamomeum y T. sp. (CBS 265.96), son más grandes que los de T. oryzae, T. roseum y Tritirachium. sp. (CBS 473.93), permitiendo presuntivamente colocar los aislados en uno de estos 2 grupos, sin embargo existe cierta sobreposición de algunas características morfológicas entre T. dependens y $T$. cinnamomeum y entre $T$. oryzae y $T$. roseum.

Paecilomyces formosus (Sakag., May. Inoue \& Tada) Houbraken \& Samson, comb. nov. MycoBank MB512562;

Basionimo. Monilia formosa Sakag., May. Inoue \& Tada, Zentralbl. Bakteriol.,2. Abt. 100: 302. 1939.

= Paecilomyces maximus C. Ram, Nova Hedwigia 16: 306. 1968.

= Paecilomyces lecythidis C. Ram (as lecythisii), Nova Hedwigia 16:307.1968.

Este hongo presenta colonias de rápido crecimiento en MEAa $25^{\circ} \mathrm{C}$, que cubre la mayor parte de la placa en 7días, de color café pálido y borde blancos (Fig.2A), reverso café; en MEA a $37^{\circ} \mathrm{C}$, menor crecimiento, 50-60 mm en 7 días.Conidióforos ramificados en forma irregular, desordenados, hialinos a levemente cafesosos, fiálides en forma de frasco que terminan en un collula delgada, 14-
$22 \mu \mathrm{m}$ de largo (Fig.2D).Conidios variables, elipsoidales a cilíndricos, oliva-cafe, todos con una base trunca 3,2-5,5(8) x 2-3(-3,5) $\mu \mathrm{m}$ (Fig. 2D recuadro). Clamidosporas abundantes, redondas a piriformes, pigmentadas de color café pálido a oscuro, de paredes gruesas, sobre un corto o largo pedúnculo, muy abundantes en el agar y en la base del micelio aéreo (Fig. 2B-C). En CREA escaso desarrollo pero con producción de ácido bajo la colonia. Temperatura maxima $41-42^{\circ} \mathrm{C}, \mathrm{Al}$ contrario que P.variotii s. st. no crece a $45^{\circ} \mathrm{C}$.

En la descripción de las clamidosporas en el trabajo de Houbraken \& Samson, (2009), estos autores no presentan una fotografía ni datos de su alta o baja frecuencia en los cultivos. Como nuestra cepa, presentó una enorme producción de estas estructuras que dominaron los cultivos en PDAy MEA sobre la presencia del anamorfo, esta situación, nos hizo dudar si realmente correspondía a esta especies u otra csemejante. Por lo cual se envió al CBS para un estudio de biología molecular, el cual confirmó esta especie (CBS-.SP 13.002).

Ram (1968), describe 2 spp. Paecilomyces lecythidis y $\boldsymbol{P}$. maximus, en base a sus características de cultivo y el largo de sus conidios. Hobraken \& Samson (2009), en un análisis de las especies de Byssochlamys y sus anamorfos en Paecilomyces resistentes al calor, redefinen a Monilia formosa como $\boldsymbol{P}$. formosus mediante secuencias de ITS y parte de los genes que codifican proteínas ( $\beta$-tubulina y calmodulina), mostrando que $\boldsymbol{P}$. formosus puede consistir en una especie críptica que incluye, $\boldsymbol{P}$. formosus, $P$. lecythidis y $P$. maximus, indistinguibles morfológicamente. Una de las diferencia entre las spp. que pertenecen a la clade ' $\boldsymbol{P}$. maximus' y otros miembros de este diverso grupo, es el rápido crecimiento de esta especie a $37^{\circ} \mathrm{C}$ más que a $30{ }^{\circ} \mathrm{C}$. $\boldsymbol{P}$. lecythidis y $\boldsymbol{P}$. maximus, producen similares perfiles de extrolitos, mientras el extipo de cultivo de $\boldsymbol{P}$. formosus está degenerado y es un débil productor de extrolitos. Debido a esto, los últimos autores proponen que las 2 primeros taxones deben colocarse en sinonimía con $\boldsymbol{P}$. formosus, hasta que se estudien más especies que permitan una mejor delimitación polifásica.

Es fácil confundir por sus similitudes morfológicas P.variotii con P.formosus y la diferencia mayor es su consistencia en la producción de ácido en CREA y su temperatura (no crece a $45^{\circ} \mathrm{C}$ ). Houbraken et al. (2010), aplicando los datos taxonómicos más recientes, reanalizaron 34 cepas clínicas aisladas y morfológicamente determinadas como $\boldsymbol{P}$ variotii o P.lilacinum. Al emplear la biología molecular en su identificación, mediante secuencias intergénicas de las regiones de espacios de transcripción 1 y 2, incluyendo 5.8S DNAr y una parte del gen de la beta tubulina, pudieron observar que solo 14 cepas correspondían a $\boldsymbol{P}$. variotii $s$. st.,11cepas a $\boldsymbol{P}$. formosus, y 1 cepa a $\boldsymbol{P}$. dactylethromorphus. Lo que sugiere que $\boldsymbol{P}$. formosus es frecuente en muestras clínicas tan comunmente como $\boldsymbol{P}$. variotii s. st. Incluso la susceptibilidad in vitro frente a anfotericina B es similar 

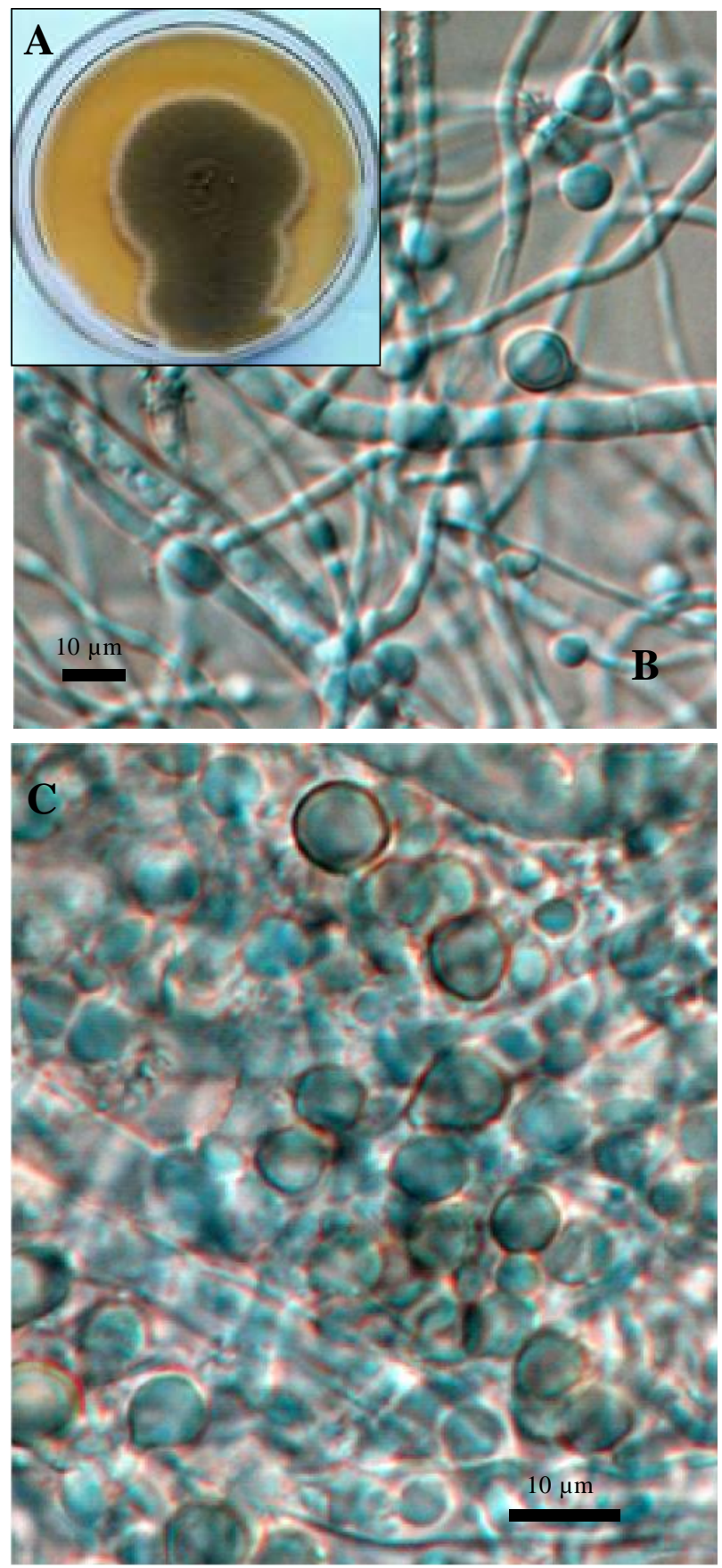

en estas 3 especies de Paecilomyces, mientras Purpureocillium lilacinus, Talaromyces. eburneus y Hamigera avellanea, presentan diferentes perfiles de susceptibilidad, siendo activas frente a la flucitosina y el voriconazol. Estos autores destacan la importancia de una correcta identificación a nivel de specie, por su importancia en la terapia antifúngica.

P. formosus se ha aislado desde suelos tropicales y madera, áire, esponjas y el hombre (médula ósea y sangre), en el aire en los dormitorios (Denmark) y en las macetas de plantas de Senseviera trifasciata (Dinamarca), desde acacia

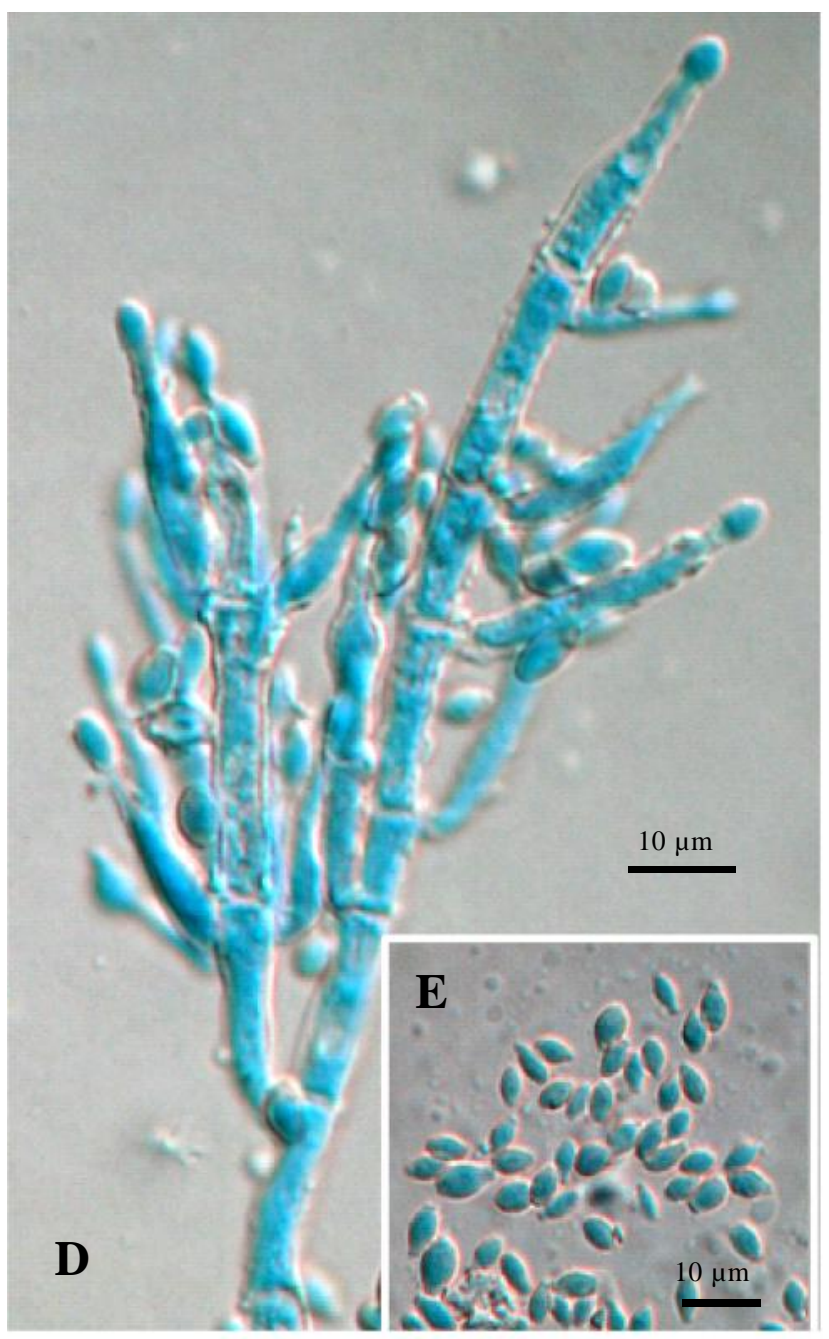

Fig.2. A-B-C-D.E. Paecilomyces formosus. A Colonia en malta alos 7 dìas a $25^{\mathrm{a}} \mathrm{C}$, B-C. Inicio e clamidosporas sobre cortos o largos pedúnculos (C .formación en masas en el agar) D. Conidiòforos y conidios E.Conidios lisos subovoides a clavados.

(Acacia nilotica ssp. Indica) en Australia (Haque et al. 2012); asociadas con inyecciones de un lote contaminado de acetato de Metilprednisolona (Andes \& Casadeval 2013. Nuestro aislamiento, se obtuvo de una muestra de áire en Santiago.

Khan et al., 2012), identificaron una cepa endófita CSH6H de Paecilomycesformosus LHL10 en pepino, bajo estrés de salinidad, aplicando análisis filogenético desecuencia similares de ITS. Los resultados revelaron que las interacciones mutualísticas de las fitohormonas secretadas por los hongos endofíticos, pueden mejorar el crecimiento de las plantas y aliviar el efecto adverso del estrés salino pudiendo en el futuro ser usadas para aumentar la productividad agrícola bajo estas condiciones. Al mismo tiempo, descubrieron que los aislados endófitos 
de $\boldsymbol{P}$.formosus, producen giberelinas e indol ácido acético. Byssochlamys y las relacionadas cepas dePaecilomyces se presentan comunmente y se han aislado previamente de varios tipos de alimentos, tales como los pasteurizados y alimentos que contienen sorbatos. La taxonomía de $\boldsymbol{P}$. variotii y especies relacionadas se ha investigado mediante métodos polifásicos con resultados que indican que Paecilomyces sensu stricto, inclye nueve species, cinco de las cuales forman un teleomorfo. $\boldsymbol{B}$. fulva, B. lagunculariae, B. nivea, B. spectabilis y $B$. zollerniae, mientras cuatro son asexuales, llamadas: $\boldsymbol{P}$. brunneolus, $\boldsymbol{P}$. divaricatus, $\boldsymbol{P}$. formosus y $\boldsymbol{P}$. dactylethromorphus. Cada especie, tiene perfiles específicos de extrolitros,además de conocerse sus potenciales en la producción de micotoxinas en cada especie. Byssochlamys nivea, produces la micotoxina patulina y el ácido bissoclamico, asì como el inmunosupresor àcido micofenólico, Algunas cepas de P. dactyelethromorphus producen patulina y brefeldina A, mientras B. spectabilis (anamorfo $=\boldsymbol{P}$. variotii s.s.) producen viriditoxina. (Houbraken et al., 2013).

\section{La Sección Fumigati de Aspergillus con énfasis en el complejo Aspergillus viridinutans}

La Section Fumigati del género Aspergillus, es una de las más abundantes en especies de todas las secciones del género, incluye integrantes de amplia importancia en medicina, farmacología, biotecnología, alimentos, así como en la ecología de los suelos (Balajee et al, 2005; Samson et al, 2006-2007; Domsh et al, 2007; Hong et al, 2008; Hubka et al, 2012). Muchas de sus especies muestran altos niveles de variabilidad intraespecífca y sobreposición de sus estructuras morfológicas, además de sus estrechos parentescos filogenéticos que a menudo se consideran como especies crípticas. Numerosos acercamientos se han propuesto para la taxonomía de esta sección, ya sea en sus estados heterotálicos como homotálicos los cuales se describen en la literatura bajo complejas definiciones de species (Hong et al., 2005-2008; Samson et al, 2007; Hubka et al, 2012-2013).

Es indudable que esta sección puede incluir aún en el tiempo un indeterminado número de especies o complejos de especies, acorde al aumento del número de aislados clínicos o ambientales analizados en diversas regiones del mundo, sujetos a las variadas presiones ambientales de sus particulares nichos ecológicos. Es una carrera en el tiempo donde los estudios morfológicos y fisiológicos se han sumado a la biología molecular en un campo que esta última ha permitido aumentar el número de integrantes en esta sección a niveles no pensados en el pasado, revolucionado las ciencias y los conceptos de lo que consideramos una especie biológica en Eucariontes.(Taylor et al., 2000; Leslie \& Bowden, 2008; Stielow et al, 2011)
Debido a la dominancia de las especies heterotálicas como A.fumigatus en los casos de aspergilosis, los datos morfofisiológicos siguen siendo los más empleados en el diagnósticos a nivel de especie en la sección Fumigati en los laboratorios de casi todo el mundo, aún en conoci-miento de las limitantes, debido a las semejanzas de su fenotipo, con especies estrechamente relacionadas y su limitada utilidad para inferir relaciones filogenéticas entre los integrantes de esta sección (Geiser et al, 1998). Estas situaciones, hacen necesario recurrir para su acercamiento a datos auxiliares fisiológicos (temperatura y crecimiento en medios de cultivos, asimilaciones, extrolitros, etc.) así como la ayuda de la biología molecular. Por el contrario, la inducción de estructuras sexuales, en las especies heterotálicas, en especial las ascosporas, presentan datos muy informativos que han permitido mediante cruza-mientos sistemático de tipos parentales opuestos, descubrir nuevas especies como es el caso del teleomorfo de A.fumigatus (= Neosartorya fumigata)(O.Gorman et al., 2009), como también en $\boldsymbol{A}$. lentulus, que posee un ciclo sexual funcional recientemente descubierto (Swilai-man et al.2013),con producción de cleistotecios y ascosporas resistentes al calor, las cuales se producen después de 3 semanas de incubación a $25^{\circ} \mathrm{C}$. No podemos dejar de mencionar que existe una amplia variación en la fertilidad de los aislados de esta especie en dependencia del compañero de cruzamiento, similar a las observaciones reportadas en A.fumigatus por O'Gorman et al,(2009). Sin embargo, los aislados de A. lentulus no se cruzaron con las cepas fértiles de A. fumigatus, lo que demuestra un aislamiento reproductivo entre estas especies hermanas. Este nuevo descubrimiento tiene implicaciones significativas en el manejo de la resistencia a drogas y el control de la aspergilosis invasiva en este emergente patógeno.

Si bien es cierto que, $A$. fumigatus sigue siendo el patógeno oportunista dominante y uno entre los más comunes en diversos ambientes (Samson et al.,2007; Klick 2002, Domsch et al, 2007), fue prácticamente la única especie considerada patogénica en humanos y otros animales entre los Aspergillus de la sección Fumigati. hasta los 2 últimos decenios del siglo 20. En el transcurso del tiempo, nuevas especies con capacidades oportunistas o saprotrofas se descubrieron en la sección, varias de ellas mediante nuevos aislamientos o reidentificaciones de colecciones de cultivos mediante métodos moleculares (Peterson, 1992-2008; Hubka, 2011), Entre ellas podemos mencionar: Aspergillus fischerianus (=Neosartorya fischeri), Aspergillus thermomutatus (=Neosartorya pseudofischeri), A. lentulus, descrito como patógeno relacionado con $A$. fumigatus, $A$ novofumigatus, $A$ udagawae (=N. udagawae) y el complejo A .viridinutans (Samson et al, (2006) Balajee et al. 2005a-b -2007; Montenegro et al, 2009; Vinh, et al, 2009; Peláez et al, 2013), Aspergillus felis (Barrs et al., 2013; Novakova et al. 2013), Aspergillus aureolus y A. wyomingensis 

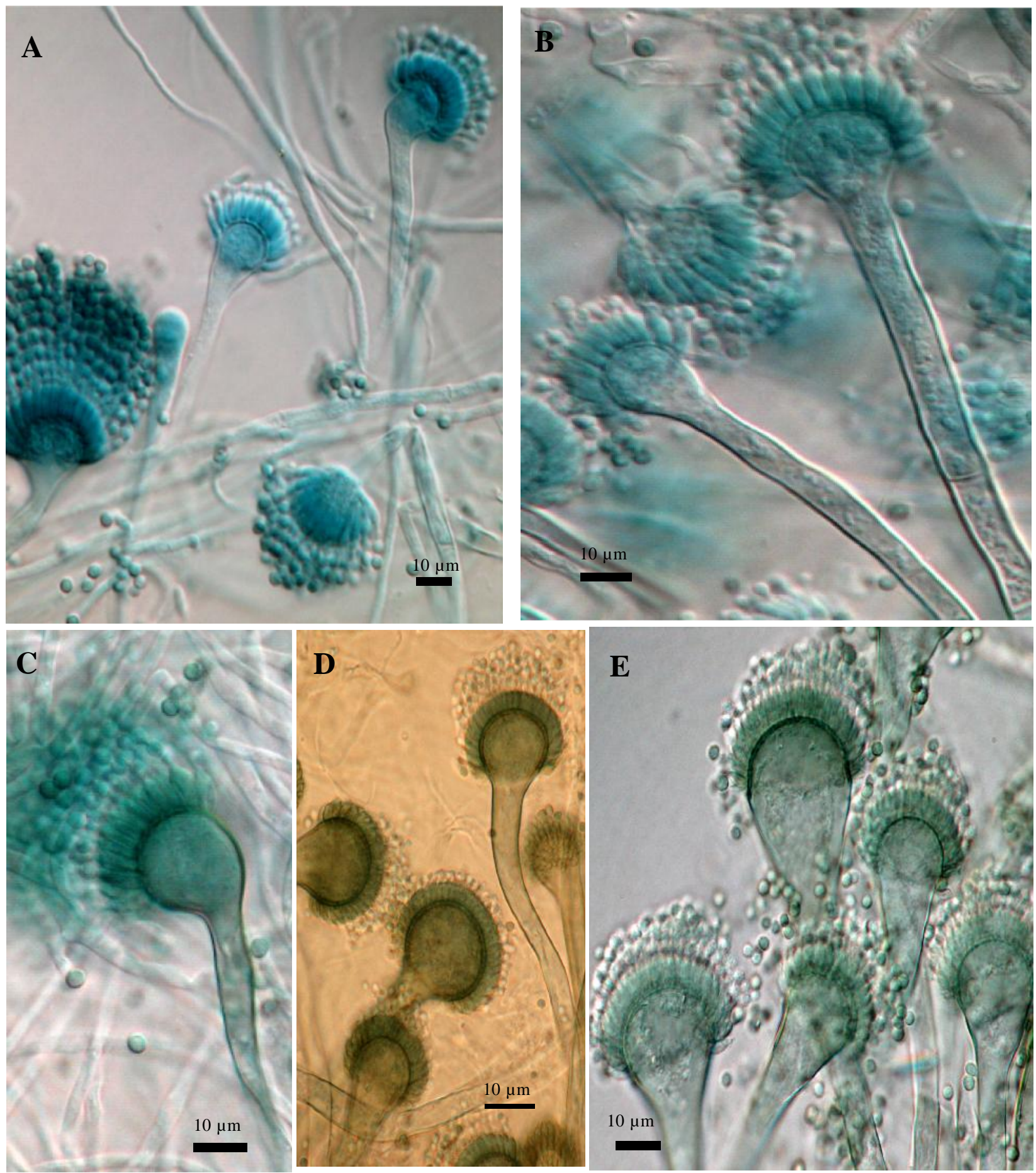

Figuras 3. A.Aspergillus udagawae, conidióforos derechos y con vesículas en ángulo, ocasionalmente presentes, conidios, B. Aspergillus A. fumigatiaffinis, conidióforos y conidios. C. Aspergillus felis, cabeza conidial y conidios, D-E. Aspergillus fumigatus, conidios y conidióforos, mostrando en D cambios morfológicos en sus vesículas .

(Novakova et al. 2013). Aspergillus waksmanii y Aspergillus marvanovae (Hubka et al, 2013).

A. fumigatus es variable en su macro y micromorfología y no es fácil separarlo de otras especies

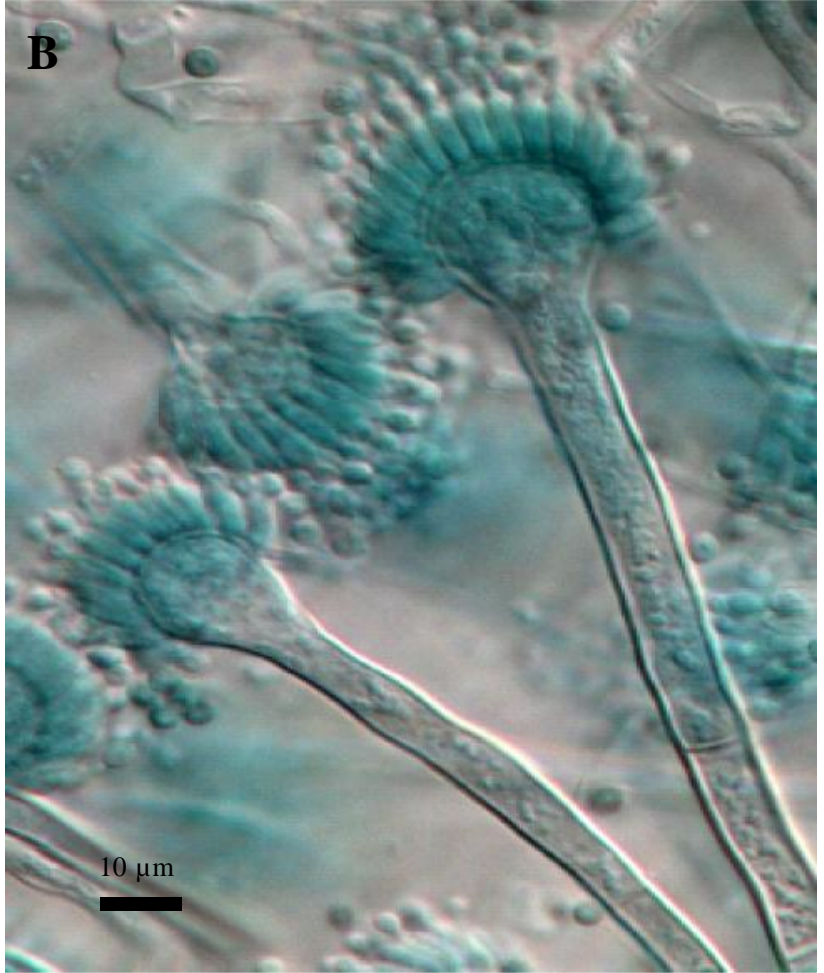


mientras A.fumigatus se caracteriza por tener usualmente vesículas subclavadas (Fig. 3E). Debido a esta variabilidad fenotípica, los errores en la identificación de las especies dentro de la sección Fumigati se han reportado frecuentemente en clínica. A. lentulus, $A$ viridinutans, $A$. fumigatiaffinis, A. fumisynnematus, A. thermomutatus, (=Neosartorya pseudofischeri), A. hiratsukae (=N. hiratsukae) у A. udagawae (=N. udagawae), se reportan frecuentemente como A.fumigatus. Hong et al. (2010), revisando 146 cepas de $\boldsymbol{A}$.fumigatus de todoel mundo (que incluyeron más de un $65 \%$ de muestras clínicas), un $95.8 \%$ fueron identificadas comos A. fumigatus s st., 2.1\% como A.lentulus, y 3 como: A. viridinutans, A. udagawae y $\boldsymbol{A}$. nishimura(e=N.nishimurae), lo que demuestra que la sola morfología o fisiología, no siempre puede llegar a una correcta identificación en A. fumigatus (Balajee et al., 2005a-2006- 2009; Serrano et al, 2011).

Muchos aislados hetero y homotálicos de la sección, semejan fuertemente A. fumigatus, pero demuestran un crecimiento lento a $37^{\circ} \mathrm{C}$ o una baja esporulación en los cultivos y no crecen generalmente a $50^{\circ} \mathrm{C}$, pero si a $47^{\circ}, 45^{\circ} \mathrm{C}$ o solo hasta $42^{\circ} \mathrm{C}$, como es el caso específico de A.udagawae, que es capaz de crecer a $10^{\circ} \mathrm{C}$ pero no puede crecer a más de $42^{\circ} \mathrm{C}$ y sus conidios necesitan un largo período de incubación para germinar a $37^{\circ} \mathrm{C}$. Esto sugiere que son más susceptibles al ataque de los neutrófilos y al peróxido de nitrógeno, lo que disminuye su virulencia y permite apreciar la sutil distinción causada por estas 2 especies. A. fumigatus, por el contrario es capaz de crecer hasta $55^{\circ} \mathrm{C}$ pero no a $10^{\circ} \mathrm{C}$, y sus conidios germinan rápidamente (Sugui et al, 2010). Sin embargo, mediante análisis de secuencias de multilocus, estos integrantes pueden semejarse fenotípicamente a varias especies relacionadas con A.fumigatus, pero filogenéticamente son distintas.

En el estudio considerado clásico en biología molecular con el empleo de multiples genes, Yaguchi et al. (2007), demostraron que las especies dentro de la sección Fumigati aisladas de especímenes clínicos en Japón, pueden ser divididas en 5 clados. El clado I: incluye las típicas cepas de A. fumigatus y las especies en sinonimía (vea Samson et al, 2007), el clado II, incluye A. lentulus y A. fumisynnematus (Horie et al. 1993); el clado III, incluye A. fumigatiaffinis y A. novofumigatus; el clado IV, incluye $\boldsymbol{A}$. viridinutans y especies estrechamente relacionadas ( Katz et al.1998; Varga et al. 2000) y el clado V, A. brevipes, A. duricaulis y A. unilateralis. Como es de esperar, la mayoría de las especies integraron el clado I, seguido del clado II y IV . Al mismo tiempo se analizó la correlación entre morfología, máxima temperatura de crecimiento y concentración inhibitoria mínima frente a los agentes antifúngicos, así como su filogenia dentro de la sección Fumigati, mientras la microscopía electrónica demostró que la ornamentación de los conidios de los aislados que pertenecen al clado $\mathbf{I}$ y $\mathbf{V}$ puede tener una forma lobadareticulada (Kozakiewicz 1989), los integrantes de la especie críptica $A$. viridinutans, son intermediarios entre lobadoreticulados y microtuberculados. Todas las cepas en el clado II y los 6 aislados variables que se presentaron en el clado IV, tienen conidios con ornamentación microtuberculada. Estos autores encontraron además que estas 6 cepas están estrechamente relacionadas con A.udagawae (= N. udagawae), sin embargo, los cruzamientos entre estas cepas no se presentaron en el tiempo, debido quizás a la dificultad de emplear rutinariamente subcultivos, pero puede tambièn asociarse a que esta especie posea una decreciente habilidad de producir ascomatas fértiles, como sucede con A.fumigatus (O'Gorman et al. 2009). Al mismo tiempo, las máximas temperaturas de crecimientos, también fueron investigadas en los clados I, II, III, IV y $\mathbf{V}$, las cuales fueron $50{ }^{\circ} \mathrm{C}, 45^{\circ} \mathrm{C}, 45{ }^{\circ} \mathrm{C}, 42{ }^{\circ} \mathrm{C}$ y $42{ }^{\circ} \mathrm{C}$, respectivamente, lo que indica que estos datos fisiológicos pueden ser útiles en la clasificación de las especies actuales o por describir dentro de la sección Fumigati de Aspergillus, como es el caso de las 2 nuevas especies: Aspergillus waksmanii y Aspergillus marvanovae, que crecen a $47^{\circ} \mathrm{C}$ (Hubka et al, 2013). Esta misma situación que emplea la temperatura, se corrobora en el trabajo anterior de Balajee et al,(2007).

En referencia a la especie críptica $A$. viridinutans, originalmente denominada solo como A.viridinutans, pero integrada por aislados morfológicamente similares, que no fueron bien definidos hasta el principio de este nuevo siglo. Esta especie críptica, fue aislada de excrementos de conejo en Australia (McLennan, et al., 1957) y posteriormente desde varios tipos de suelo, incluyendo los semidesérticos de sud América o los dañados después de la minería del carbón en USA, como también los reportados desde análisis retrospectivos de colecciones de cultivos en varias partes del mundo, (Vargas et al, 2000; Piontelli et al.2000; Eltem et al. 2004; Yaguchi et al. 2007; AlcazarFuoli et al. 2008; Giusiano et al.2013 en revision), resaltando que varios de sus integrantes se han aislados como oportunistas en humanos. (Vinh et al., 2009; Hong et al., 2010; Shigeyasu et al., 2012; Peláez et al. 2013). Se destaca que la micromorfología del complejo es variable, en relación a sus conidios y sus conidióforos, especialmente en la presencia de sus vesículas en ángulo ('nodding appearence'), una situación que no es exclusiva del complejo como comenta Nováková et al., (2013), debido a que se observa en otros representantes de la sección Fumigati como: A. brevipex, A.duricaulis, A. marvanovae, A.unilateralis, A. thermomutatus (=Neosartorya pseudofischeri) y las 2 nuevas especies recientemente descritas A.brevistipitatus y A. conversis (Nováková et al., (2013). Vargas et al. 2000, lo consideró un carácter morfológico distintivo para la identificación de las especies dentro de los Aspergillus de la sección Fumigati; por el contrario, para Balajee et al. (2006), su sola presencia no es un carácter determinante sin la asociación de mayores datos fisiológicos y moleculares. En el complejo A.viridinutans, la descripción de sus integrantes en base a 
morfología es altamente variable en los aislados presuntivamente asignados. Éstos pueden presentar colonias de crecimiento relativamente rápido en 7 días en $\mathrm{CYA} 25^{\circ} \mathrm{C}$ y MEA, Todas crecen relativamente bien a $37^{\circ} \mathrm{C}$ en CREA, salvo A.viridinutans s.st. (18-21 mm) y en general, no todas producen ácido. Su temperatura máxima oscila entre $\operatorname{los} 42^{\circ} \mathrm{C} \mathrm{y} 45^{\circ} \mathrm{C}$.

En relación a las especies integrantes (A.viridinutans s.st. lo hace solo hasta $42^{\circ} \mathrm{C}$ y parece ser una especie poco común, solo aislada en Australia), las colonias son de un color verde grisáceo, de esporulación limitada desde abundante micelio aéreo, reverso en CYA incoloro, amarillo a levemente café; cabezas columnares con conidióforos derechos o sinuosos generalmente sobre los 60-100 $\mu \mathrm{m}$, que nacen del micelio aéreo, a veces con presencia de algunos septos, vesículas clavadas, en forma de frasco a subglobosas, generalmente menores de $20 \mu \mathrm{m}$, algunas desviadas notoriamente en ángulo (Fig.3D); conidios globosos a subglobosos, delicadamente rugosos a lisos, 2-3 $\mu \mathrm{m}$. Vargas et al. (2000), detectaron una variabilidad intraespecífica de los integrantes del complejo A.viridinutans al emplear técnicas morfológicas, fuentes carbonadas, análisis de restricción de enzimas de mitocondrias, DNA nuclear y secuencias de B-tubulina. Determinaron además, que la distancia genética entre las cepas de A.viridinutans, A. aureoluteus (=N.aureola) y A. udagawae $(=N$.udagawae $)$, pertenecen a un mismo grupo, una situación que se confirma también en A.felis (Barrs et al.2013).

En cuanto a la patología humana de los Aspergillus de esta sección, excluyendo a A.fumigatus y en referencia especial al complejo A. viridinutans, Vinh et al. (2009), demostraron que esta especie puede causar distintas formas de aspergilosis, caracterizada por cronicidad, propensión a la dispersión de manera contagiosa entre diversos planos anatómicos, y un comportamiento refractario frente a los antimicóticos. Por el contrario, la aspergilosis invasora afecta pacientes neutropénicos sometidos a quimioterapia o pacientes trasplantados, actuando típicamente como una enferemedad aguda con predilección por la angioinvasión y la diseminación hematógena. Presentan una respuesta exitosa frente a los antimicóticos, generalmente entre las 6 semanas de tratamiento (Wingard et al., 2008), Sin embargo, las infecciones por el coplejo A.viridinutans en 2 pacientes con una inmunodeficiencia primaria, sugieren que este fenómeno clínico refleja una inherente estructura patogénica del hongo, más que una manifestación debida a un específico defecto inmune, situación ya demostrada en otra especie relacionada cladísticamente como A.udagawae, en pacientes con una enfermedad como la granulomatosis crónica o la mielodisplasia (Vihn et al., 2009b.). Esto sugiere diferencias patogénicas entre los subgrupos dentro de la sección Fumigati y debido a esto, la identificación genotípica de estos hongos miméticos de
A.fumigatus, pueden tener implicaciones en el curso clínico de la enfermedad así como en su manejo.

Barrs et al. (2013), describen en gatos domésticos una rinosinusitis invasiva fúngica y una aspergilosis invasiva diseminada en un perro, así como una una nueva especie heterotálica en el complejo A.viridinutans que denominan A.felis (anamorfo de neosartorya), donde las enfermedades en ambos hospedadores fueron a menudo refractarias a la terapia agresiva clásica antifúngica (Itraconazol, Variconazol).A. felis es un hongo heterotálico con un total ciclo reproductivo funcional (sexual) confirmado por análisis de cruzamientos que inducen el teleomorfo en 7-10 días in vitro con germinación de ascosporas, además, tiene la máxima capacidad de crecer hasta $45^{\circ} \mathrm{C}$, y a menos de $20^{\circ} \mathrm{C}$, lo que lo separa de $\boldsymbol{A}$ fumigatus $\left(>50^{\circ} \mathrm{C}\right.$ ) y de $A$ viridinutans s. st. y A.udagawae, que tiene un límite a los $42^{\circ} \mathrm{C}$ (Yaguchi et al, 2007; Sugui et al., 2010). La rinosinusitis fúngica en gatos domésticos, puede deberse también a varias especies como: A.fumigatus, A.udagawae, A. lentulus, A. thermomutans y A.fumigatiaffinis, todas con un alto CIM a multiples antifúngicos (Anfotericina B y Voriconazol).Estas especies, se han descrito también en humanos como resistentes a todos los azoles. (Balaje et al .2009; Alcazar-Fuoli et al, 2008; Peláez et al, 2013). En contraste, la mayoría de estas especies tienen bajo CIM frente al Posaconazol. Es importante el estudio de más aislados para entender mejor la susceptibilidad in vitro de las diferentes especies dentro de la sección Fumigati (Balajee et al., 2009).

Otros casos de aspergilosis invasora se han presen-tado en pacientes con leucemia por especies crípticas de Aspergillus, donde se aisló: $\boldsymbol{A}$. novofumigatus y Aspergillus viridinutans (Peláez et al, 2013). Shigeyasu et al. (2012), describen un primer caso de queratitis causado por A.viridinutans, con manifestaciones clínicas distintas a las de $\boldsymbol{A}$. fumigatus, las cuales incluían resistencia clínica a la anfotericina B y el voriconazol, con baja susceptibilidad a otros agentes fúngicos. Barrs et al. (2013) y Nováková et al. (2013), demostraron que los casos humanos de aspergilosis invasiva diagnosticados como A.viridinutans por: Coehlo et al. 2011; Yaguchi et al. 2007; Alcazar-Fuoli, et al. 2008; Vinh et al.2009; Barrs et al.2012-2013; Shigeyasu et al. 2012; Peláez et al.2013, entre otros), corresponden a A.felis, lo que demuestra el aumento de esta especie en clínica junto a A. udagawae (Katz et al. 2005; Balajee et al. 2006; Vinh et al.2009b; Yaguchi et al. 2007; Kano et al. 2008; Balajee et al.2009; Posteraro et al. 2011; Gyotoku et al. 2012; Kano et al.2013).

Desde el punto de vista Molecular, el nivel de discriminación entre las species de la sección Fumigati (y algunas otras secciones del género) es relativamente baja en las ITS, pero se considera el estándar y pueden trabajarse (Serrano et al. 2011; Jurjevic et al. 2012; 
Novákova' et al., 2012; Peterson, 2012). Como las ITS no permiten distinguir estos aislados entre sí (Alcazar-Fuoli et al.2008), las secuencias de $\beta$-tubulina y calmodulina, o los genes de rodlet $A$, permiten la identificación de todos ellos y en especial pueden diferenciar los aislados atípicos de A.fumigatus (Balajee et al.2005- 2007; Hong et al. 2005; Samson et al. 2007; Vinh et al. 2009; Serrano et al.2011), en especial los integrantes del complejo A. viridinutans, considerados desde más de una década en la literatura con extremas diferencias en la variación de secuencias de DNA (Katz et al,1998-2005; Vargas et al, 2000; Yaguchi et al, 2007).

Recientemente, Nováková et al. (2013), analizaron el complejo mediante 2 diferentes métodos de identificación: PCR (datos de secuencias de $\beta$-tubulina (benA) y genes de calmodulina ( $c a M)$, macro y micromorfología (microscopía electrónica óptica y escaner), temperaturas máxima de crecimiento y experimentos de cruzamiento. Estos últimos ensayos, junto a los análisis filogenéticos y morfología de las ascosporas, sugieren la presencia de 5 especies en el complejo A.viridinutans: A aureolus (= Neosartorya aureola), la única especie homotálica. $\boldsymbol{A}$. felis, A. udagawae (=N. udagawae) y A. wyomingensis sp. nov. son heterotálicas, todas con su teleomorfo distinguible. A viridinutans s. st. parece ser una especie. muy rara, representada solo por su extipo de aislamiento, donde su locus MAT1-1 fue amplificado. A.viridinutans y A. aureolus fueron tipificados en concordancia con las reglas del nuevo código botánico con las descripciones completas de sus 5 integrantes, aportando además una clave dicotómica para este complejo, que reproducimos aquí con mayores datos. Sin embargo, su empleo requiere de cepas compatibles en las especies heterotálicas para su cruzamiento, lo que complica su uso, siendo necesarios siempre recurrir a los datos moleculares (vea : Nováková et al, 2013).

1.- Cultivos homotálicos, ascosporas lenticulares (4)4,5$5 \mu \mathrm{m}$, con dos crestas ecuatoriales bien separadas (1$1,5 \mu \mathrm{m}$ de ancho), equinuladas a tuberculadas, conidios ampliamente subglobosos, delicadamente rugosos, $2,1-2,8 \mu \mathrm{m}$, crece a $42^{\circ} \mathrm{C}$, no a $45^{\circ} \mathrm{C}, \mathrm{CREA} 28-43$ $\mathrm{mm}$, débil producción de ácido bajo las colonias, Ehrlich negativo.............A.aureolus Fennel \& Raper

- Cultivos heterotálicos o anamórficos ............. 2

\section{2.- Colonias en MEA después de 7 días a $25^{\circ} \mathrm{C}<\operatorname{de~} 35 \mathrm{~mm}$;} conidióforos en MEA $<120 \mu \mathrm{m}$, conidios globosos a subglobosos, 2-2,8 $\mu \mathrm{m}, \mathrm{t}^{\circ}$ máxima $42^{\circ} \mathrm{C}$, CREA 18-21 $\mathrm{mm}$, sin producción de ácido, Ehrlich negativo.......

A.viridinutans Ducker \& Thrower - Colonias en MEA >de 35mm; al menos algunos conidióforos En MEA> de 120 $\mu \mathrm{m}$ ...3
3.- Ascosporas sin crestas ecuatoriales o con pequeñas crestas $<0,2 \mu \mathrm{m}$, conidios subglobosos, delicadamente rugosos, 1,7-2,8 (-3.3) $\mu \mathrm{m}, \mathrm{t}^{\circ}$ máxima $42^{\circ} \mathrm{C}$, restringida a $45^{\circ} \mathrm{C}$, solo algunos aislados $(16 \mathrm{~mm})$, CREA 46-50 mm, producción de ácido fuerte o solo bajo la colonia, Ehrlich negativo

.......A.wyomingensis A.Nováková, Dudová \& Hubka - Ascosporas con 2 crestas ecuatoriales claramente distinguibles ( $>0,5 \mu \mathrm{m}$ de ancho). 4

4.- Crestas ecuatoriales mas angost as que $1 \boldsymbol{\mu m}$, conidios subglobosos a elipsoides, lisos, 2,4-3,2um, $\mathrm{t}^{\circ}$ máxima $42^{\circ} \mathrm{C}$, algunos aislamientos crecen lento a $45^{\circ} \mathrm{C}(7 \mathrm{~mm})$, CREA 46-50mm, sin producción de ácido en algunos aislados, a muy fuerte producción en otros, Ehrlich negativo.

A.udagawae Horie,Miyaji \&Nishim.

- Crestas ecuatoriales más anchas, que $1 \boldsymbol{\mu m}$, conidios ampliamente subglobosos, delicadamente rugosos, 2,3-2,8 $\mu \mathrm{m}$, CREA 40-55 mm, sin ácido, Ehrlich negativo a violeta muy pálido... A. felis Barrs, van Doorn, Vargas \& Samson.

Estos autores pudieron observar otras especies que fueron tipificadas fuera del complex A.viridinutans, aisladas desde terrenos reutilizables después de la minería del carbón (Wiomung U.S.A), tales como: A. fumigatiaffinis y A.lentulus como también 2 especies hermanas, A. brevistipitatus sp. nov. yA. conversis sp. nov., muy relacionadas entre sí y entre $A$. papuensis (=N. papuensis). Ambas nuevas especies son distantes filogenéticamente de todas las especies anamórficas y se parecen a $\boldsymbol{A}$. brevipes, $A$. duricaulis y A. unilateralis en su micromorfología, sin embargo, se distinguen entre ellas, por el lento crecimiento de A. conversis en todos los medios estudiados. Como datos interesante, estos autores no encontraron ningún aislado de A. fumigatus s. str., usualmente reportado como el dominante en el suelo.

\section{REFERENCIAS}

Alcazar-Fuoli,L.; Mellado,E.;Alastruey-Izquierdo,A.;Cuenca-Estrella, M.; Rodriguez-Tudela, J,L. (2008). Aspergillus section Fumigati: antifungal susceptibility patterns and sequencebased identification. Antimicrob Agents Chemother.;52:1244-51. DOI: $10.1128 / A A C .00942-07$

Andes, D. \& Casadevall, A.(2013). Insights into fungal pathoge-nesis from the iatrogenic epidemic of Exserohilum rostratum fungal meningitis, Fungal Genet. Biol. http://dx.doi.org/10.1016/j.fgb.2013.08.014

Balajee, A.; Gribskov,J.; Brandt, M. et al., (2005a), Mistaken Identity:Neosartorya pseudoûscheri and Its Anamorph Masquerading as Aspergillus fumigates. J.Clin. Microbiol. 43:5996-5999

Balajee, S.A.; Gribskov, J.L.; Hanley, E.; Nickle, D.; Marr KA. (2005b).Aspergillus lentulus sp nov, a new sibling species of A. fumigatus. Eukaryot Cell 4:635-632 
Balajee, A.S.;Nickle,D.;Varga,J. \& Marr,A.K.(2006). Mole-cular Studies Reveal Frequent Misidentification of Aspergillus fumigates by Morphotyping. Eukaryotic.5:1705. DOI: 10. 1705-1712.

Balajee, S.A.; Houbraken, J.; Verweij, P.E.; Hong, S.B, Yaguchi, T.;Varga,J,et al.(2007). Aspergillus species identification in the clinical setting. Stud. Mycol. 59:39-46

Balajee, S.A. et al., (2009). Molecular Identification of Aspergillus Species Collected for the Transplant-Associated Infection Surveillance Network J. Clin. Microbiol. 47:3138-3141

Barrs, R.V.; van Doorn, M.T.; Houbraken, J. et al., (2013). Aspergillus felis sp. nov., an Emerging Agent of Invasive Aspergillosis in Humans, Cats, and Dogs. PLOS ONE 8(6): e64871. doi:10.1371/ journal.pone.0064871

Beguin, H. (2010). Tritirachium egenum, a thiamine-and siderophore-auxotrophic fungal species isolated from Penicillium rugulosum. FEMS Microbiology Ecology 74:165-173

Beguin,H.; Pyck,N.\&; Detandt,M.(2012). Tritirachium, a hyphomycetous genus belonging to the Basidiomycota.Nova Hedwigia, 94:139-152

Carmichael,J.W.;Kendrick, W.B.; Conners, I.L. ;Sigler, L. (1980) Genera of Hyphomycetes.Univ Alberta Press.Edmonton.

Coelho, D.; Silva, S.; Vale-Silva, L.;Gomes, H.et al. (2011). Aspergillus viridinutans: an agent of adult chronic invasive aspergillosis. Med Mycol 49:755-759

de Hoog, G.S. 1972. The genera Beauveria, Isaria, Tritirachium and Acrodontium gen.nov. Stud Mycol 1:1-41

de Hoog, G.S. (1973). Additional notes on Tritirachium. Persoonia 7:437-441

Del Ponte, Emerson. et al. (2013). Composition of the Fusarium graminearum species complex populations in wheat cropping environments in Southern Brazil. Agricultural Research Service (Abstrat)

Domsch, K.H.; Gams, W. \& Anderson, T.H.(2007) Compendium of soil fungi, 2nd edn. IHW-Verlag, Eching

Eltem, R. et al., (2004). Colonial and Morphological Characteristics of Some Aspergillus Fr.:Fr. Species Isolated from Vineyards in Manisa and Üzmir Provinces (Turkey). Turk J. Bot.28:287-29

Gams,W, deHoog,S.G. \& Samson,R.A. (1984). The Hyphomycete genus Engyodontium a link between Verticillium and Aphanocladium. Persoonia. 12:135-147

Geiser, D. M.; Frisrad, J.C.\& Taylor, J. W. (1998). Evolutionary relationships in Aspergillus section Fumigati inferred from partial beta-tubulin and hydrophobin DNA sequences. Mycologia 90:831845

Giusiano, G.; Piontelli, E.; Mangiaterra, M.; Fernández, M.; Cattana, ME.; Kocsubé, S.; Varga, J. (2014). Biodiversity of species of Aspergillus section Fumigati in semi-desert soils in Argentina.(En revisión Fungal Diversity)

GuarroJ.; Gené,J. \& Stchigel, M.A. (1999). Developments in Fungal Taxonomy. Clin. Microbio. 12:454-500

Gyotoku, H.; Izumikawa, K.; Ikeda, H. et al. (2012) A case of bronchial aspergillosis caused by Aspergillus udagawae and its mycological features.Med Mycol 50:631-636
Haque, A. et al. (2012). A preliminary investigation of prickly acacia dieback (Acacia nilotica ssp. indica). Eighteenth Australasian Weeds Conference.

Hong, S.B.;Go,S.J.;Shin,H.D. et al. (2005). Polyphasic taxonomy of Aspergillus fumigatus and related species. Mycologia 97:1316-1329

Hong, S,B.; Shin,H:D.; Frisvald, J.C. et al. (2008). New taxa of Neosartorya and Aspergillus in Aspergillus section Fumigati. Antonie Leewenhoek 93: 87-98

Hong,S-B. et al., (2010).Re-identification of Aspergillus fumigatus sensu lato based on a new concept of species delimitation. J. Microbiol. 48:607-615

Horie, Y.; Miyaji, M.; Nishimura, K.; Taguchi, H.; Udagawa, S, (1993). Aspergillus fumisynnematus, a new species from Venezuelan soil. Transactions of the Mycological Society Japan 34:33-37

Houbraken, J.;Verweij, E,P.; Rijs, J. M. M.J. A.; Borman,M.A. \& Samson, R.A. (2010). Identification of Paecilomyces variotii in Clinical Samples and Settings. J. Clin. Microbiol., 48: 27542761

Houbraken, J.; Frisvad,J,\& Samson,R.A. (2013).Taxonomic review of food relevnt Paecilomyces variotii and related species . The ICFM workshop: Food Mycology in a Globalized World, Challenges and Solutions to the Safety of Food, Germany June 3 to 5

Hubka, V.; Kubatova, A.; Mallatova, N. et al. (2012). Rare and new aetiological agents revealed among 178 clinical Aspergillus strains obtained from Czech patients and characterised by molecular sequencing. Med. Mycol. 50:601-610

Hubka, V.;Peterson,W.S.;Frisvad,C,J. et al. (2013). Aspergillus waksmanii sp. nov. and Aspergillus marvanovae sp. nov., two closely related species in section Fumigati. International Journal of Systematic and Evolutionary Microbiology 63:783-789

Hughes, S. (1953). Conidia conidiophores and classification. Can.J. Bot.31:577-659

Hugues,B.;Pyck, N.\& Detandt, M.(2012).Tritirachium, a hyphomycetous genus belonging to the Basidiomycota. Nova Hedwigia, 94:139-152

Jurjevic, Z.; Peterson, S. W. \& Horn, B. W. (2012). Aspergillus section Versicolores: nine new species and multilocus DNA sequence based phylogeny. IMA Fungus 3, 59-79

Kano, R.; Itamoto, K.; Okuda, M.; Inokuma, H.; Hasegawa, A.; Balajee, A.(2008). Isolation of Aspergillus udagawae from a fatal case of feline orbital aspergillosis. Mycoses.51:360-361

Kano, R.; Shibahashi, A.; Fujino, Y, et al. (2013). Two cases of feline orbital aspergillosis due to Aspergillus udagawae and $\boldsymbol{A}$. viridinutans. J. Vet. Med. Sci. 75:7-10

Katz, M.E.;McLeon, M.; Burrows,S. \& Cheetham,F.B. (1998). Extreme DNA sequence in isolates of Aspergillus fumigatus. FEMS Immun. Med. Microbiol, 20:283-288

Katz. M.E.; Dougall, A.M.; Weeks, K.; Cheetham, B.F. (2005). Multiple genetically distinct groups revealed among clinical isolates identified as atypical Aspergillus fumigatus. J. Clin. Microbiol. 43:551-555

Khan.A.L; Hamayun, M.; Kang, Sang-Mo, et al. (2012). Endophytic fungal association via gibberellins and indole acetic 
Notas micológicas XI:Tritirachium oryzae, Paecilomyces formosus y alcances en la Sección Fumigati de Aspergillus - E. Piontelli et.al

acid can improve plant growth under abiotic stress: an example of Paecilomyces formosus LHL10 Khan et al. BMC Microbiology $12: 3$

Kirk, P.M.; Cannon, P.F.; Minter, D.W.; Stalpers, J.A.(2008). Dictionary of the Fungi. 10th ed. Oxon, UK: CAB International. $771 \mathrm{p}$.

Klich, M.A. (2002). Biogeography of Aspergillus species in soil and litter. Mycologia 94:21-27

Kozakakiewicz, Z. (1989). Aspergillus species in stored products. Mycological Papers 161:1-188

Kwon-Chung, J.K.; Janyce, A. \& Sugui, A.-J.(2009) Sexual reproduction in Aspergillus species of medical or economical importance: why so fastidious? Trends in Microbiology 17:481487

Leslie, J.F. \& Bowden, L. (2008). Fusarium graminearum: When species concept collide. Cereal Research Communication 36:609615

Limber, D.P. (1940). A new form genus of the Moniliaceae. Mycologia 32:23-30

Lonial, S.; Williams. L.; Carrum, G.; Ostrowski, M.; McCarthy, P. Jr. (1997). Neosartorya fischeri: an invasive fungal pathogen in an allogeneic bone marrow transplant patient. Bone Marrow Transplant. 19:753-5. PubMed PMID: 9156256

MacLeod, D.M. (1954). Investigations on the genera Beauveria Vuill. And Tritirachium Limber. Can J Bot 32:818-890

McNeill, J.; Barrie, F.R.; Buck, W.R.; Demoulin, V, et al., (2012). International code of nomenclature for algae, fungi, and plants (Melbourne Code): adopted by the Eighteenth International Botanical Congress Melbourne, Australia, July 2011. Koeltz Scientific Books, Koenigstein

McLennan, E.I.; Tucker, S.C. \& Thrower, L.B. (1954). New soil fungi from Australian heathland: Aspergillus, Penicillium, Spegazzinia. Australian Journal of Botany. 2:355-64.

Montenegro, G.; Puch, SS.; Jewtuchowicz, V.M.; Piñón, M.V.; Relloso, S, et al. (2009).Phenotypic and genotypic characterization of Aspergillus lentulus and Aspergillus fumigatus isolates in a patient with probable invasive aspergillosis. J. Med. Microbiol. 58:391-395

Moraes, R.N.; Ribeiro, M.C.; Nogueira, M.C.; Cunha, K.C.; et al. (2010). First report of Tritirachium oryzae infection of human scalp. Mycopathologia 169:257-259

Naseri, A.; Fata, A.;Javad, M. \& Najafzadeh, M.J. (2013). First Case of Tritirachium oryzae as Agent of Onychomycosis and Its Susceptibility to Antifungal Drugs.Mycopathologia 176:119-122

Nováková,A,etal.,(2013).New species in Aspergillus section Fumigati from reclamation sites in Wyoming (U.S.A.) and revision of $\boldsymbol{A}$. viridinutans complex Fungal Diversity. DOI 10.1007/s13225-013-0262-5

Novákovà, A.; Hubka, V.; Saiz-Jimenez, C. \& Kolarik, M. (2012). Aspergillus baeticus sp. nov. and Aspergillus thesauricus sp. nov., two species in section Usti from Spanish caves. Int J Syst Evol Microbiol 62:2778-2785

O'Gorman, C.M.; Fuller, H.T.; Dyer, P.S. (2009). Discovery of a sexual cycle in the opportunistic fungal pathogen Aspergillus fumigatus. Nature 457:471-474
Pakshir,K,: Rahimi, G.M.; Zomorodian,K. \& Reza, G. A.(2013).Isolation and Molecular Identification of Keratinophilic Fungi from Public Parks Soil in Shiraz, Iran. BioMed. Research International, Article ID 619576, 5 pages, doi:10.1155/ 2013/619576

Peláez, T.;Alvarez-Perez, S.;Mellado, E.;Serrano,D.;Valerio, M. et al. (2013). Invasive aspergillosis caused by cryptic Aspergillus species: a report of two consecutive episodes in a patient with leukaemia. J. Med. Microbiol. 62:474-478

Peterson,S.W.(2008).Phylogenetic analysis of Aspergillus species using DNA sequences from four loci. Mycologia 100:205-226

Peterson, S.W. (1992) Neosartorya pseudofischeri sp nov. and its relationship to other species in Aspergillus section Fumigati . Mycolog Res 1992; 96:547-554.

Peterson, S. W. (2012). Aspergillus and Penicillium identification using DNA sequences: barcode or MLST? Appl Microbiol Biotechnol .95:339-344

Peterson,W.S. (2013), Taxonomic revision of Eurotium and transfer of species to Aspergillus. Mycologia 2013 105:912-937

Piontelli, E. (2000) Notas Micológicas IV: Nuevos registros de hongos mitospóricos de suelos Chilenos. Boletín Micológico 15:93-99

Posteraro,B.; Mattei,R.; Trivella,F. et al.(2011). Ancommon Neosartoria udagawe fungus a causative agent of severe coneal infection. J. Clin. Microbiol. 49:2357-60

Ram, C. (1968). Timber-attacking fungi from the state of Maranhao, Brazil;Some new species of Paecilomyces and its perfect state Byssochlamys. Westl. VIII. Nova Hedwigia 16:305-314

Rao, B,M.; Tanksale,M.A.; Ghatge,S.M. \& Deshpande, V.V. (1998). Molecular and Biotechnological Aspects of Microbial Proteases. Microbiol.Molec. Biol. Reviews. Sept. 597-635

Rodrigues, M.M. \& Laibson, P. (1975). Exogenous corneal ulcer caused by Tritirachium roseum. Am.J.Ophthalmol. 80:804-806

Samson,R.A.; Hong,S-B, \&Frisvald, J.C. (2006). Old and new concepts of species differentiation in Aspergillus. Medical Mycology 44:S133-S148

Samson RA, Hong S, Peterson SW, Frisvad JC, Varga J (2007) Polyphasic taxonomy of Aspergillus section Fumigati and its teleomorph Neosartorya. Studies in Mycology 59:147-203

Samson, R. A.; Houbraken,J.; Varga,J. \&. Frisvad.J.C. (2009). Polyphasic taxonomy of the heat resistant ascomycete genus Byssochlamys and its Paecilomyces anamorphs. Persoonia 22:14-27

Samson,R.A. (2009).Indoor fungi and climate change. s3-euwest1.amazona ws.com/aspergillus conference eslides/educationoverflow/Samson.pdf.

Schell,A.W.; Lee,G.A M. \& Aime1,C.M. (2011).A new lineage in Pucciniomycotina: class Tritirachiomycetes, order Tritirachiales, family Tritirachiaceae. doi:10.3852/10-333

Swilaimann, S.S.; O'Gormann,M.C.;Balajeee,A.S \& Dyer, S.P. (2013). Discovery of a Sexual Cycle in Aspergillus lentulus, a Close Relative of A. fumigates. Eukaryotic Cell. 12 : 962-969

Serrano,R.; Gusmão,L.; Amorim, A. \& Araujo,R. (2011). Rapid identification of Aspergillus fumigatus within the section Fumigati. BMC Microbiology 11:82-87 
Stielow, B.; Bratek, Z.; Orczán, A.K.I.; Rudnoy, S.; Hensel G, et al. (2011) Species Delimitation in Taxonomically Difficult Fungi: The Case of Hymenogaster. PLOS ONE 6(1):e15614. doi:10.1371/journal.pone.0015614

Shigeyasu, C.; Yamada, M.; Nakamura, N.; Mizuno, Y.; Sato, T-: Yaguchi, T. (2012) Keratomycosis caused by Aspergillus viridinutans: and Aspergillus fumigatus-resembling mold presenting distinct clinical and antifungal susceptibility patterns. Med. Mycol. 50:525-528

Sugui,A.J.;Vinh C.D. \&. Nardone,G. et al., (2010).Neosartorya udagawae (Aspergillus udagawae), an Emerging Agent of Aspergillosis: How Different Is It from Aspergillus fumigatus? J. Clin, Microbiol.48:220-228

Swilaiman,S.S.;O'Gorman,M.C.;ArunmozhiS.;Balajee, S.A.; Dyera, S.P. (2013).Discovery of a Sexual Cycle in Aspergillus lentulus, a close relative of A. fumigatus .Eukaryotic Cell 12:962-969

Taylor ,W,J. et al.(2000). Phylogenetic Species Recognition and Species Concepts in Fungi. Fungal Genetics and Biology 31:21-32

Toome, Merje. \& Aime, M.C. (2011). Tritirachiomycetes. Tritirachiales, Tritirachiaceae. Version 22 November 2011 (under construction).http://tolweb.org/Tritirachiomycetes/147934/ 2011.11.22 in The Tree of Life Web Project,http://tolweb.org/

Vinh, C.D.; Shea, R. Y.; Jones, A.P. et al. (2009). Chronic invasive aspergillosis caused by Aspergillus viridinutans. Emerg. Inf. Disease. 15:1292-1294

Vinh, D.C.; Shea, Y.R.; Sugui, J.Aet al.,(2009b). Invasive aspergillosis due to Neosartorya udagawae. Clin. Infect .Dis.1;49:102-111
Van Beyma, Thoe. \& Kingma, F.H. (1942). Beschreibung einiger neuer Pilzarten aus dem Centraalburea voor Schimmelcultures, Baarn (Nederland) VII. Mitteilung. Antonie van Leeuwenhoek $8: 105-122$.

van:Wyk, P.S.; Wingfield, M.J. \& Kendrick, B. (2000). Analisis of conidiogenesis:helical conidiotaxis in percurrently extending conidiogenous cell. South African J, of Sciences. 96:580-583

Varga, J.; Tóth, B.; Rigó, K-: Debets, F.; Kozakiewicz, Z. (2000). Genetic variability within the Aspergillus viridinutans species. Folia Microbiol(Praha) 45:423-8. DOI:10.1007/ BF02817615

Wiese, J. et al., (2011). Phylogenetic Identification of Fungi Isolated from the Marine Sponge Tethya aurantium and Identification of Their Secondary Metabolites Mar. Drugs 9:561585

Wingard, J.R.; Ribaud, P.; Schlamm. H.T,\& Herbrecht, R. (2008). Changes in causes of death over time after treatment for invasive aspergillosis. Cancer. 112:2309-2312.

Wyk,S.P.van.; Wingfield, M.J. \& Kendrick,B. (2000). Analysis of conidiogénesis helical conidiotaxis in percurrently extending conidiogenous cell. South African J. of Sci. 96:580-583

Yaguchi, T.; Horie, Y.; Tanaka, R.; Matsuzawa, T.; Ito, J, et al. (2007) Molecular phylogenetics of multiple genes on Aspergillus Section Fumigati isolated from clinical specimens in Japan. Jap. J. Med. Mycol. 48:37-46

\section{CONFLICTO DE INTERESES
Los autores declaran no tener conflicto de intereses.}

